\title{
Editorial on "Neoadjuvant Chemotherapy Does Not Increase Complications in Oncoplastic Breast-Conserving Surgery"
}

\author{
Abhishek Chatterjee, MD, MBA \\ Tufts Medical Center, Boston, MA
}

In their article "Neoadjuvant chemotherapy does not increase complications in oncoplastic breast-conserving surgery", 1 Adamson et al. demonstrate the safety of performing Level 2 volume displacement oncoplastic surgery, using mastopexy and breast reduction designs, after neoadjuvant chemotherapy (NAC). In this retrospective, case-cohort comparison study, 122 patients received NAC, while 307 patients did not. Both groups had similar preoperative comorbidities, and the results showed no statistical difference in postoperative overall and major complications between the comparison groups. The overall complication rate was relatively high at $25.9 \%$, with wound healing being most common; however, the major complication rate was lower at $9 \%$. Additionally, only $5 \%$ of patients required additional surgery because of a complication. Importantly, approximately $5 \%$ of patients received a delay in their adjuvant therapy (radiation or chemotherapy) because of postoperative complications. Notably, in patients who did not receive NAC, $3.8 \%$ of patients had a delay to adjuvant radiation therapy, and $6 \%$ of patients had a delay to adjuvant chemotherapy. In patients who received NAC, $3.2 \%$ of patients had a delay to adjuvant radiation treatment. A period of 4 weeks following NAC was noted to be a safe time to perform oncoplastic surgery.

Oncoplastic surgery is a form of breast conservation involving a large partial mastectomy followed by reconstruction using volume displacement and volume replacement techniques (e.g. local flaps)., ${ }^{2,3}$ Volume displacement options are further broken down into two levels: Level 1 involves local tissue rearrangement (e.g. doughnut

(C) Society of Surgical Oncology 2019

First Received: 17 March 2019;

Published Online: 7 May 2019

A. Chatterjee, MD, MBA

e-mail: achatterjee1@tuftsmedicalcenter.org mastopexy designs), while Level 2 involves mastopexy and breast reduction designs. ${ }^{4}$ There has been increasing interest in oncoplastic surgery over the last decade, demonstrated both by practice patterns that have demonstrated a greater than twofold increase over the last decade, ${ }^{5}$ and survey data sent to practicing breast surgeons. ${ }^{6}$ With this continued rising interest, the timeliness of this article is important as the authors demonstrate the safety and possible pitfalls in performing Level 2 volume displacement oncoplastic surgery. Of note, past studies have noted the safety of NAC in breast surgery; ${ }^{7,8}$ however, none of these have specifically included oncoplastic surgery patients, which makes the article by Adamson et al. unique. The incisions made on the skin in Level 2 volume displacement oncoplastic surgery are much longer in total compared with most mastectomy incisions, and the need for local tissue healing after massive tissue rearrangements is immense (especially when using breast reduction designs), making the study on the impact of NAC on healing in this specific patient population important. Furthermore, the authors go into specific detail with regard to the rates and types of complications that a patient may encounter when undergoing Level 2 volume displacement oncoplastic operations after NAC. Such information is important to set postoperative expectations when counseling patients, and can also facilitate the discussion about operative choices when several surgical options present for a given clinical presentation. Based on the results from this paper, a patient undergoing Level 2 volume displacement oncoplastic surgery (with or without NAC) should be counseled that while complications can be at rates of approximately $25 \%$, most of these complications are not major and involve some form of wound healing, infection, fat necrosis, or hematoma/seroma (mentioned in decreasing order of frequency). Additionally, patients should know that $5 \%$ of these operations may require further surgery to treat these complications. 
Within the result's multivariate regression analysis, body mass index (BMI) and diabetes were noted to be risk factors for postoperative complications. These make sense and have been noted in prior breast surgery literature. ${ }^{9}$ However, bilateral surgery had a statistically significant association, with fewer complications compared with unilateral surgery. Logically, this makes no sense. Past studies have noted that more surgery typically leads to a higher rate of complications; ${ }^{10,11}$ therefore, this particular result is likely to be a type 1 statistical error given the small numbers present comparing unilateral versus bilateral surgery and assessing complications.

Overall, this is a very useful research article that will aid the breast surgeon advocating for oncoplastic surgery. Patients and surgeons can be rest assured that this surgical option is available and safe following NAC.

\section{REFERENCES}

1. Adamson M, Chavez-MacGregor M, Caudle A, Smith B, Baumann D, Liu J, Schaverien M. Neoadjuvant chemotherapy does not increase complications in oncoplastic breast-conserving surgery. Ann Surg Oncol. 2019. https://doi.org/10.1245/s10434-01907408-6.

2. Losken A, Hart AM, Chatterjee A. Updated evidence on the oncoplastic approach to breast conservation therapy. Plast Reconstr Surg. 2017;140(5S Advances in Breast Reconstruction): $14 \mathrm{~S}-22 \mathrm{~S}$.

3. Chatterjee A, Gass J, Patel K, Holmes D, Kopkash K, Peiris L, et al. A consensus definition and classification system of oncoplastic surgery developed by the american society of breast surgeons. Ann Surg Oncol. Epub 11 Apr 2019. https://doi.org/10. 1245/s10434-019-07345-4.

4. Clough KB, Kaufman GJ, Nos C, Buccimazza I, Sarfati IM. Improving breast cancer surgery: a classification and quadrant per quadrant atlas for oncoplastic surgery. Ann Surg Oncol. 2010;17(5):1375-91.

5. Jonczyk MM, Jean J, Graham R, Chatterjee A. Surgical trends in breast cancer: a rise in novel operative treatment options over a 12 year analysis. Breast Cancer Res Treat. 2019;173(2):267-74.

6. Chatterjee A, Gass J, Burke MB, Kopkash K, El-Tamer MB, Holmes DR, et al. Results from the American Society of Breast Surgeons Oncoplastic Surgery Committee 2017 Survey: current practice and future directions. Ann Surg Oncol. 2018;25(10):2790-4.

7. Decker MR, Greenblatt DY, Havlena J, Wilke LG, Greenberg CC, Neuman HB. Impact of neoadjuvant chemotherapy on wound complications after breast surgery. Surgery. 2012;152(3):382-8

8. Azzawi K, Ismail A, Earl H, Forouhi P, Malata CM. Influence of neoadjuvant chemotherapy on outcomes of immediate breast reconstruction. Plast Reconstr Surg. 2010;126(1):1-11.

9. Jonczyk MM, Jean J, Graham R, Chatterjee A. Trending towards safer breast cancer surgeries? Examining acute complication rates from a 13-year NSQIP analysis. Cancers. 2019;11(2):253.

10. Pyfer B, Chatterjee A, Chen L, Nigriny J, Czerniecki B, Tchou J, et al. Early postoperative outcomes in breast conservation surgery versus simple mastectomy with implant reconstruction: a NSQIP analysis of 11,645 patients. Ann Surg Oncol. 2016;23(1):92-8.

11. Chatterjee A, Pyfer B, Czerniecki B, Rosenkranz K, Tchou J, Fisher C. Early postoperative outcomes in lumpectomy versus simple mastectomy. J Surg Res. 2015;198(1):143-8.

Publisher's Note Springer Nature remains neutral with regard to jurisdictional claims in published maps and institutional affiliations. 